\title{
THE EFFECTS OF PARAMETRIC UNCERTAINTIES IN SIMULATIONS OF A REACTIVE PLUME USING A LAGRANGIAN STOCHASTIC MODEL
}

\author{
Tilo Ziehn, Nick S. Dixon and Alison S. Tomlin
}

Energy and Resources Research Institute (ERRI), University of Leeds, LS2 9JT, UK

\begin{abstract}
A combined Lagrangian stochastic model with micro mixing and chemical sub-models is used to investigate a reactive plume of nitrogen oxides $\left(\mathrm{NO}_{\mathrm{x}}\right)$ released into a turbulent grid flow doped with ozone $\left(\mathrm{O}_{3}\right)$. Sensitivities to the model input parameters are explored for high $\mathrm{NO}_{\mathrm{x}}$ model scenarios. A wind tunnel experiment is used to provide the simulation conditions for the first case study where photolysis reactions are not included and the main uncertainties occur in the parameters defining the turbulence scales, the source size and the reaction rate of $\mathrm{NO}$ (nitric oxide) with $\mathrm{O}_{3}$. Using nominal values of the parameters from previous studies, the model gives a good representation of the radial profile of the conserved scalar $\left[\mathrm{NO}_{\mathrm{x}}\right]$ compared to the experiments, although the width of the simulated profile is slightly smaller, especially at longer distances from the source. For this scenario, the Lagrangian velocity structure function coefficient has the largest impact on simulated $\left[\mathrm{NO}_{\mathrm{x}}\right]$ profiles. At the next stage photolysis reactions are included in a chemical scheme consisting of eight reactions between species $\mathrm{NO}, \mathrm{O}, \mathrm{O}_{3}$ and $\mathrm{NO}_{2}$. The high dimensional model representation (HMDR) method is used to investigate the effects of uncertainties in the various model inputs resulting from the parameterisation of important physical and chemical processes in the reactive plume model, on the simulation of primary and secondary chemical species concentrations. Both independent and interactive effects of the parameters are studied. In total 22 parameters are assumed to be uncertain, among them the turbulence parameters, temperature dependant rate parameters, photolysis rates, temperature, fraction of $\mathrm{NO}$ in total $\mathrm{NO}_{\mathrm{x}}$ at the source and background concentration of $\mathrm{O}_{3}$. Only uncertainties in the mixing time scale coefficient and the structure function coefficient are responsible for the variance in the $\left[\mathrm{NO}_{\mathrm{x}}\right]$ radial profile. On the other hand, the variance in the $\left[\mathrm{O}_{3}\right]$ profile is caused by parameters describing both physical and chemical processes.
\end{abstract}

Key words: Sensitivity analysis, high dimensional model representation, $\mathrm{NO}_{2}$, ozone, Lagrangian structure function coefficient.

\section{INTRODUCTION}

Lagrangian stochastic models are now widely used to model mean concentrations and concentration fluctuations in atmospheric plumes. In this work a combined Lagrangian stochastic model with a micro mixing sub-model (Dixon and Tomlin, 2007) is used. This model was not only designed for open terrain simulations but also for predicting concentration fluctuations in urban areas. It is based on the marked particle model, which uses the formulation of Thomson (1987) for inhomogeneous turbulent flows. The diffusion term is consistent with the Lagrangian velocity structure function to first order if the diffusion term $b_{i j}$ is set to

$$
b_{i j}=\sqrt{c_{0} \varepsilon} \delta_{i j}
$$

where $c_{0}$ is a constant (structure function coefficient) and $\varepsilon$ the dissipation rate of turbulent kinetic energy $k$. A mixing model is included to calculate the evolution of the particle's concentration. In order to close the model the mixing timescale $t_{m}$ has to be specified and is related to the turbulence time scale using

$$
t_{m}=\alpha \frac{k}{\varepsilon}
$$

where $\alpha$ is a constant (mixing time scale coefficient). The model has been tested against the open terrain wind tunnel data of Fackrell, J.E. and A.G. Robins (1982) where the mean concentration and fluctuation intensity could be reproduced. The model was also coupled with the urban flow model MISKAM (Eichhorn, 1996) and compared with the wind tunnel simulations of a two dimensional street canyon by Pavageau and Schatzmann (1999), also showing good agreement. Limited sensitivity studies exploring the impact of the model parameters were carried out in Dixon and Tomlin (2007) but only for a selected ensemble of simulations. The current work extends this previous analysis by applying the model to a reactive plume scenario and by extending sensitivity studies to the use of global sensitivity methods, which can explore large regions of the input parameter space.

\section{GLOBAL SENSITIVITY ANALYISIS USING HDMR}

The high dimensional model representation (HDMR) method is a set of tools explored by Rabitz et al. (1999) to express the input-output relationship of complex models with large numbers of input parameters. The mapping between input parameters $x_{1}, \ldots, x_{n}$ and output variables $f(\mathbf{x})=f\left(x_{1}, \ldots, x_{n}\right)$ in the domain $R^{n}$ is written in the form:

$$
f(\mathbf{x})=f_{0}+\sum_{i=1}^{n} f_{i}\left(x_{i}\right)+\sum_{1 \leq i<j \leq n} f_{i j}\left(x_{i}, x_{j}\right)+\ldots+f_{12 \ldots n}\left(x_{1}, x_{2}, \ldots, x_{n}\right)
$$

Here $f_{0}$ denotes the mean effect (zeroth order), which is a constant. The function $f_{I}\left(x_{i}\right)$ is a first order term giving the effect of parameter $x_{i}$ acting independently (although generally nonlinearly) upon the output $f(\mathbf{x})$. The function $f_{i j}\left(x_{i}, x_{j}\right)$ is a second order term describing the cooperative effects of the parameters $x_{i}$ and $x_{j}$ upon the output $f(\mathbf{x})$. The higher order terms reflect the cooperative effects of increasing numbers of input parameters acting together to influence the output $f(\mathbf{x})$. The HDMR expansion is computationally very efficient if higher order input variable 
correlations are weak and can therefore be neglected. For many systems a HDMR expression up to second order already provides satisfactory results and a good approximation of $f(\mathbf{x})$. Here, we have applied RS-HDMR, where the component functions are approximated by orthonormal polynomials. The standard RS-HDMR approach has been extended by an optimisation method (Ziehn and Tomlin, 2008a), which automatically chooses the best polynomial order for the approximation of each of the component functions and by a threshold, which automatically excludes unimportant component functions (Ziehn and Tomlin, 2008b).

The partial variances $D_{i}$ and $D_{i j}$ for sensitivity analysis purposes are easily calculated from the HDMR component functions ( $\mathrm{Li}, \mathrm{G}$. et al., 2002b). Once the partial variances are determined sensitivity indices can be calculated as follows:

$$
S_{i}=\frac{D_{i}}{D}, \quad S_{i j}=\frac{D_{i j}}{D}
$$

where $D$ is the total variance. The first order sensitivity index $S_{i}$ measures the main effect of the input variable $x_{i}$ on the output, or in other words the fractional contribution of $x_{i}$ to the variance of $f(\mathbf{x})$. The second order sensitivity index $S_{i j}$ measures the interaction effect of $x_{i}$ and $x_{j}$ on the output and so on. Once calculated the sensitivity indices can be ranked in order to explore the relative contribution of the input parameters to the overall variance in the predicted outputs e.g. predicted species concentrations at a given spatial point, integrated concentrations etc.

\section{REACTIVE PLUME MODEL}

The Lagrangian stochastic model by Dixon and Tomlin (2007) can also be applied for reacting gas concentrations. Particles are initially placed randomly throughout the domain, with concentration assigned only to those particles that pass through the source. The mixing model is then used to simulate the spread of concentration between neighbouring particles, which is crucial to accurately predict the concentration fluctuations. Operator splitting is used so that after each flow and mixing time-step a chemical reaction step is performed, in this case using a stiff equation solver (a Rosenbrock method). The chemical rate equations and the Jacobian matrix have to be provided in the code.

\section{Model Validation and Uncertainties for Brown and Bilger Plume}

The wind tunnel experiment by Brown and Bilger (1996) is used to provide the first case study for a reacting plume. The nominal mean axial velocity of the flow is $\overline{\mathbf{U}}=0.5 \mathrm{~ms}^{-1}$. It is doped with $\mathrm{O}_{3}$ (background $\left[\mathrm{O}_{3}\right]=2.45 \times 10^{13} \mathrm{molcm}^{-3}$ ) and well mixed. The velocity of the point source is matched to $\overline{\mathbf{U}}$ and consists of $\mathrm{N}_{2}$ doped with NO (source $[\mathrm{NO}]=1.26 \times 10^{16} \mathrm{molcm}^{-3}$ ). The reactants undergo the reaction $\mathrm{NO}+\mathrm{O}_{3}=\mathrm{NO}_{2}+\mathrm{O}_{2}$. Photolysis reactions are not included due to the absence of ultraviolet light. Using the nominal values for the source size $(\sigma=0.008 \mathrm{~m}$, assuming a Gaussian distribution), the mixing time scale coefficient $(\alpha=0.75)$ and the structure function coefficient $\left(c_{0}=5\right)$ obtained from Dixon and Tomlin (2007), the model gives a good representation of the radial profile of the concentration of conserved scalar $\mathrm{NO}_{\mathrm{x}}=\mathrm{NO}+\mathrm{NO}_{2}$ compared to the wind tunnel experiment. However, the simulated profile is slightly narrower especially at longer distances from the point source as shown in Figure 1. The results from the simulations show a very good match with the experimental data around the plume centre for both radial profiles of $\mathrm{NO}_{\mathrm{x}}$.

Error bars are also shown in Figure 1 based on 400 simulations, where $\mathcal{c}_{0}$ has been varied between [3.. 6], $\alpha$ between $[0.6 \ldots 3]$ and $\sigma$ between $[0.008 \ldots 0.016] \mathrm{m}$. The structure function coefficient $c_{0}$ determines the effective turbulent diffusion in velocity space, and plays an important role in Lagrangian dispersion modelling. As pointed out in Rizza,U. et al. (2006) a wide range of values are found in the literature, which have been determined under different assumptions. The range for $c_{0}$ used here is estimated on the basis of a number of earlier studies such as Rizza et al. (2006), Lien and D'Asaro (2002) and Du (1997). The lower value of 3 and the proposed universality of $c_{0}$ suggested in Du (1997) were questioned by Reynolds (1998) and therefore it is of interest to explore the impact of uncertainties in this parameter. The possible range for describing the mixing timescale is based on Cassiani et al. (2005) who reviewed the range of values used in the literature in Table 1 of their paper. The range for is estimated to represent the uncertainty in the effect of near field mixing on the initial source width. The error bars therefore represent the limits of uncertainty in the predictions of $\mathrm{NO}_{\mathrm{x}}$ profiles based on the ranges of previous estimates for the turbulence constants. Figure 1 shows that although the peak values are represented we do not recover the experimental values at the plume edge for the radial $\mathrm{NO}_{\mathrm{x}}$ profiles. The figure also shows that the nominal values selected give a good representation of the experimental data but that if broad input ranges are considered then the range of predictions is quite large. This indicates a high degree of sensitivity to the input parameters, which will be explored further using sensitivity analysis in the following section. 


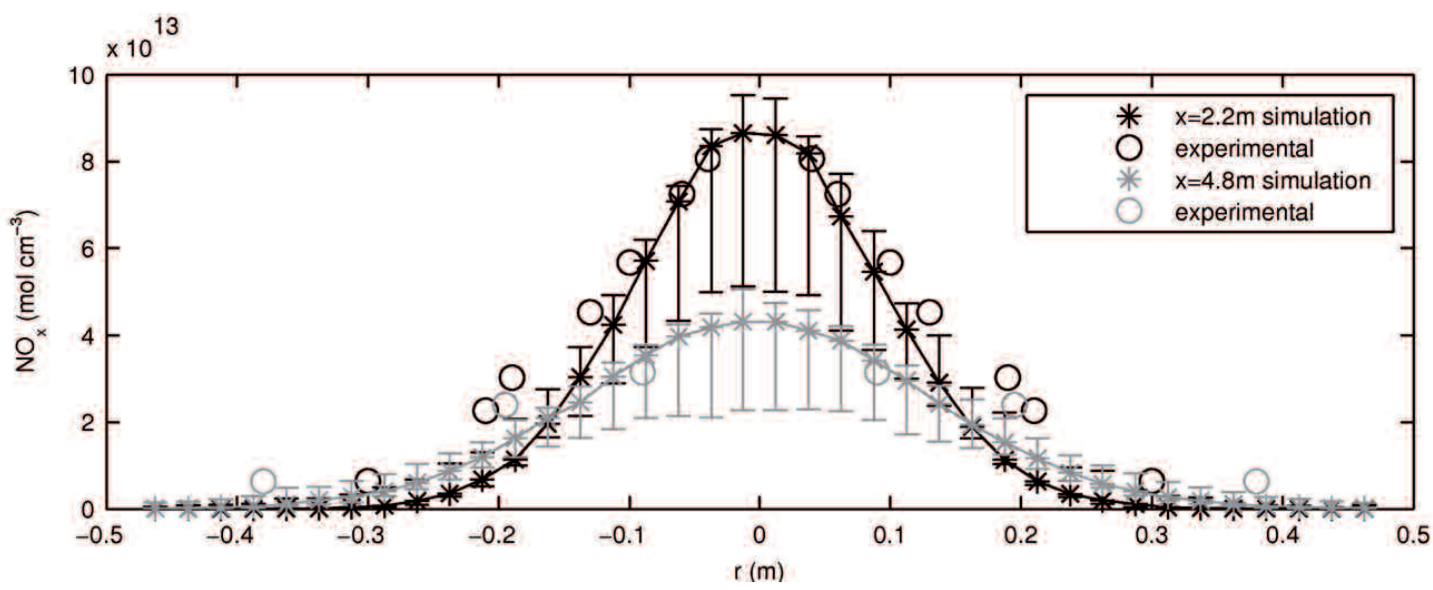

Figure 1. Radial profiles of mean $\left[\mathrm{NO}_{\mathrm{x}}\right]$ at $x=2.2 \mathrm{~m}$ and $x=4.8 \mathrm{~m}$ from the point source obtained from simulations (using the nominal values for $\sigma, \alpha$ and $\mathcal{c}_{0}$ ) and from wind tunnel experiments (Brown and Bilger, 1996).

\section{Sensitivity Analysis and Results}

At the next stage the chemical reaction scheme has been extended to eight reactions between the species $\mathrm{NO}, \mathrm{O}, \mathrm{O}_{3}$ and $\mathrm{NO}_{2}$ as shown in Table 1. Photolysis has also been included for $\mathrm{O}_{3}$ and $\mathrm{NO}_{2}$. The physical and chemical processes in the reactive plume are then investigated in order to study the effects of possible uncertainties in the parameters. In total 22 parameters are assumed to be uncertain, among them $c_{0}, \alpha$ and $\sigma$ as above, as well as the chemical reaction rate parameters for each reaction (A factor, activation energy $E$ and temperature coefficient for Arrhenius parameters or photolysis rate), temperature, background $\left[\mathrm{O}_{3}\right]$ and fraction of $\mathrm{NO}$ in total $\mathrm{NO}_{\mathrm{x}}$ at the source. The ranges for the uncertain parameters were defined according to a minimum and maximum value, assuming equal probability throughout the ranges. The maximum and minimum values for the Arrhenius parameters are in accordance with Atkinson et al. (2004). The uncertainty ranges for the photolysis rates are obtained from Shetter et al. (1992) and Shetter et al. (1996). Uncertainties for the temperature were assumed to be within the range of $[273 \ldots 293] \mathrm{K}$. The range for NO fraction in the source (initial concentration $[\mathrm{NO}]=1.26 \times 10^{16} \mathrm{molcm}^{-3}$ ) was varied from 1 to 0.8 in order to assess the impact of uncertainties of primary $\mathrm{NO}_{2}$ in $\mathrm{NO}_{\mathrm{x}}$ sources which is also of relevance to transport related emissions of $\mathrm{NO}_{\mathrm{x}}$. The concentration for ozone has been varied in between $\left[7.350 \times 10^{11} \ldots\right.$ $1.225 \times 10^{12} \mathrm{molcm}^{-3}$. The ozone concentration has been chosen to be lower than the one in the experiment of Brown and Bilger (1996) in order to provide a more realistic atmospheric scenario.

Table 1. Chemical reaction scheme as used in the reactive plume model. Reaction rates for nos. 1-6 are obtained from Atkinson et al. (2004) no. 7 from Shetter et al. (1996) and no. 8 from Shetter et al. (1992).

\begin{tabular}{|l|l|l|l|l|l|l|l|}
\hline No. & Reaction & No. & Reaction & No. & Reaction & No. & Reaction \\
\hline 1 & $\mathrm{O}=\mathrm{O}_{3}$ & 3 & $\mathrm{O}+\mathrm{O}_{3}=2 \mathrm{O}_{2}$ & 5 & $\mathrm{O}+\mathrm{NO}_{2}=\mathrm{NO}$ & 7 & $\mathrm{O}_{3}=\mathrm{O}$ \\
\hline 2 & $\mathrm{O}=\mathrm{O}_{3}$ & 4 & $\mathrm{O}+\mathrm{NO}=\mathrm{NO}_{2}$ & 6 & $\mathrm{NO}+\mathrm{O}_{3}=\mathrm{NO}_{2}$ & 8 & $\mathrm{NO}_{2}=\mathrm{NO}+\mathrm{O}$ \\
\hline
\end{tabular}

The HDMR software package (Ziehn and Tomlin, 2008c) has been applied in order to perform global sensitivity analysis and to calculate variance based sensitivity indices for the 22 input parameters based on the uncertainty ranges described above. The software combines the RS-HDMR tools in one Matlab package equipped with a graphical user interface, which makes the HDMR method easily available for all interested users.

Table 2. First order sensitivity indices for $\left[\mathrm{NO}_{\mathrm{x}}\right]$ at the plume centre at different distances $x$ away form the point source.

\begin{tabular}{|l|c|c|c|}
\hline Parameter & $S_{i}$ for $x=2.2 \mathrm{~m}$ & $S_{i}$ for $x=4.8 \mathrm{~m}$ & $S_{i}$ for $x=5.8 \mathrm{~m}$ \\
\hline Structure function coefficient $c_{0}$ & 0.7997 & 0.8039 & 0.8023 \\
\hline Mixing time scale coefficient $\alpha$ & 0.1868 & 0.1864 & 0.1876 \\
\hline$\Sigma S_{i}$ & 0.9866 & 0.9903 & 0.9900 \\
\hline
\end{tabular}

The outputs of interest for the sensitivity analysis are the concentrations of the conserved scalar $\mathrm{NO}_{\mathrm{x}}$ and $\mathrm{O}_{3}$ at the plume centre at different distances $x$ away from the point source. A quasi-random sequence of the size $N=2048$ has been used in connection with the HDMR analysis and for the calculation of the sensitivity indices. Table 2 presents the first order sensitivity indices for $\left[\mathrm{NO}_{\mathrm{x}}\right]$. Since $\mathrm{NO}_{\mathrm{x}}$ is a conserved tracer and the initial $\left[\mathrm{NO}_{\mathrm{x}}\right]$ is the same as in the previous section, then these results effectively provide a sensitivity analysis of the variance expressed by the error bars in figure 1. No interactions between parameters (second order effects) could be found and only two parameters have an influence on the output variability. The structure function coefficient $c_{0}$ is the most important parameter and is responsible for $80 \%$ of the variance in peak $\left[\mathrm{NO}_{\mathrm{x}}\right]$. The mixing time scale coefficient accounts for almost $19 \%$ of 
the overall variance. The sensitivity to the two parameters is similar for all three investigated distances $x$ from the source. There is a low sensitivity to the initial source size. HDMR component functions for each parameter allow the investigation of individual effects in more detail. The component functions for $c_{0}$ and $\alpha$ with respect to the $\mathrm{NO}_{\mathrm{x}}$ concentration at the plume centre and for $x=2.2 \mathrm{~m}$ are shown in Figure 2. Scatter plots from a Monte Carlo simulation based on randomly selected input parameters are also shown for comparison. This highlights the advantage of the HDMR component functions, since they show directly the effect of each parameter on the selected output. It can be seen that a strong positive linear relationship exists between $c_{0}$ and $\left[\mathrm{NO}_{\mathrm{x}}\right]$, whereas the effect of $\alpha$ is negative and nonlinear. The experimental value is also highlighted in Figure $2 \mathrm{a}$ and demonstrates that even taking into account uncertainties in other parameters, the experimental concentration is not recoverable with a value of $\mathcal{c}_{0}$ as low as 3 .
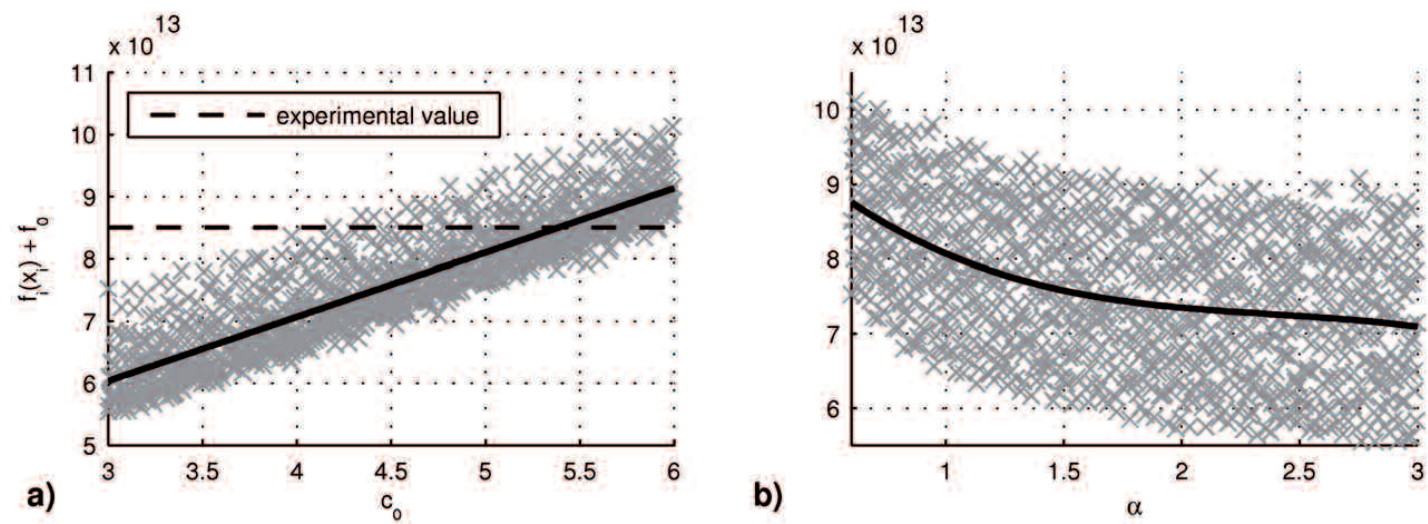

Figure 2. First order component functions and scatter plots for (a) the structure function coefficient $c_{0}$ and (b) the mixing time scale coefficient $\alpha$ with respect to $\left[\mathrm{NO}_{\mathrm{x}}\right]$ at the plume centre for $\mathrm{x}=2.2 \mathrm{~m}$. The mean $f_{0}$ is added to $f_{i}$ for comparison with scatter plot.
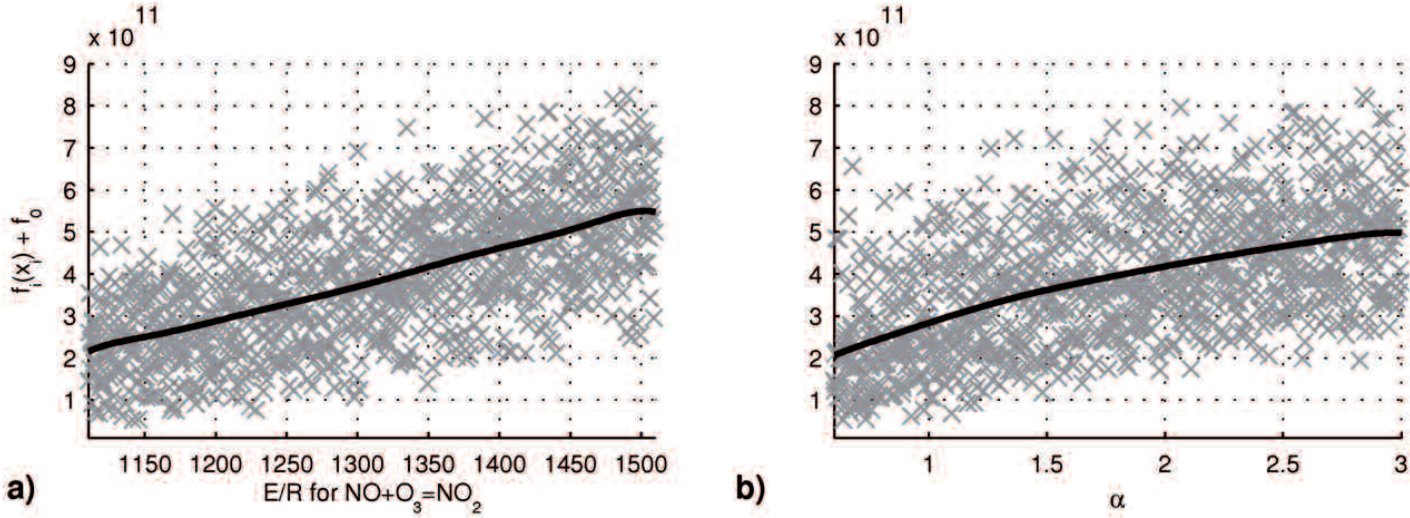

Figure 3. First order component functions and scatter plots for (a) $E / R$ for $\mathrm{NO}+\mathrm{O}_{3}=\mathrm{NO}_{2}$ and (b) the mixing time scale coefficient $\alpha$ with respect to $\left[\mathrm{O}_{3}\right]$ at the plume centre for $x=2.2 \mathrm{~m}$. The mean $f_{0}$ is added to $f_{i}$ for comparison with scatter plot.

Table 3. First order sensitivity indices for $\left[\mathrm{O}_{3}\right]$ at plume centre. The numbers in brackets indicate the ranking of the parameter.

\begin{tabular}{|c|c|c|c|}
\hline Parameter & $S_{i}$ for $x=2.2 \mathrm{~m}$ & $S_{i}$ for $x=4.8 \mathrm{~m}$ & $S_{i}$ for $x=5.8 \mathrm{~m}$ \\
\hline$E / R$ for $\mathrm{NO}+\mathrm{O}_{3}=\mathrm{NO}_{2}$ & $0.4086(1)$ & $0.4302(1)$ & $0.4330(1)$ \\
\hline Mixing time scale coefficient & $0.3030(2)$ & $0.2693(2)$ & $0.2594(2)$ \\
\hline Background concentration for $\mathrm{O}_{3}$ & $0.1057(3)$ & $0.0749(4)$ & $0.0708(4)$ \\
\hline Fraction of $\mathrm{NO}$ in total $\mathrm{NO}_{\mathrm{x}}$ & $0.0591(4)$ & $0.0776(3)$ & $0.0834(3)$ \\
\hline Temperature & $0.0335(5)$ & $0.0359(6)$ & $0.0362(6)$ \\
\hline Structure function coefficient $c_{0}$ & $0.0296(6)$ & $0.0363(5)$ & $0.0373(5)$ \\
\hline A factor for $\mathrm{NO}+\mathrm{O}_{3}=\mathrm{NO}_{2}$ & $0.0276(7)$ & $0.0292(7)$ & $0.0295(7)$ \\
\hline$\Sigma S_{i}$ & 0.9745 & 0.9643 & 0.9620 \\
\hline
\end{tabular}

Table 3 shows the first order sensitivity indices for $\left[\mathrm{O}_{3}\right]$. In total seven parameters are responsible for the variance of the output. The most important parameter is the activation energy term $E / R$ for the reaction $\mathrm{NO}+\mathrm{O}_{3}=\mathrm{NO}_{2}$, which contributes more than $40 \%$ to the overall variance. Now that interactions between turbulent mixing and chemical reaction are included, the most important turbulence parameter becomes $\alpha$ which defines the mixing timescale. 
Parameter interactions were not found as shown by the total first order sensitivity coefficients adding to almost 1 . The importance of the parameters, and even the ranking, changes with growing distance $x$ from the source. For example, the fraction of NO in total $\left[\mathrm{NO}_{\mathrm{x}}\right]$ becomes more important at further distances $x$ from the source and its rank changes from 4 to 3 . The plot of the component functions for the two most important parameters is presented in Figure 3. The relationship between $E / R$ for the reaction $\mathrm{NO}+\mathrm{O}_{3}=\mathrm{NO}_{2}$ and $\left[\mathrm{O}_{3}\right]$ is nearly linear (positive) whereas the relationship between $\alpha$ and $\left[\mathrm{O}_{3}\right]$ is fairly nonlinear (positive).

\section{CONCLUSIONS}

The variance in the mean concentration of the conserved scalar $\left[\mathrm{NO}_{\mathrm{x}}\right]$ at the plume centre is as expected only influenced by the turbulence parameters $c_{0}$ and $\alpha$. The sensitivity to those parameters is constant throughout the investigated distances $x$ from the point source with the structure function dominating the output variance. In contrast, the variance in mean $\left[\mathrm{O}_{3}\right]$ is influenced by both physical and chemical parameters. A total of seven parameters contribute independently to the overall variance with the mixing timescale coefficient now being the dominant turbulence parameter and the activation energy for the reaction $\mathrm{NO}+\mathrm{O}_{3}=\mathrm{NO}_{2}$ dominating the kinetic sensitivities.

\section{REFERENCES}

Atkinson, R., D.L. Baulch, R.A. Cox, J.N. Crowley, R.F. Hampson, R.G. Hynes, M.E. Jenkin, M.J. Rossi and J. Troe, 2004: Evaluated kinetic and photochemical data for atmospheric chemistry: Volume I - gas phase reactions of $\mathrm{O}_{\mathrm{x}}, \mathrm{HO}_{\mathrm{x}}, \mathrm{NO}_{\mathrm{x}}$ and $\mathrm{SO}_{\mathrm{x}}$ species. Atmospheric Chemistry and Physics, 4, 1461-1738.

Brown, R.J. and R.W. Bilger, 1996: An experimental study of a reactive plume in grid turbulence. Journal of Fluid Mechanics, 312, 373-407.

Cassiani, M., P. Franzese and U. Giostra, 2005: A PDF micromixing model of dispersion for atmospheric flow. Part I: development of the model, application to homogeneous turbulence and to neutral boundary layer. Atmospheric Environment, 39, 1457-1469.

Dixon, N.S. and A.S. Tomlin, 2007: A Lagrangian stochastic model for predicting concentration fluctuations in urban areas. Atmospheric Environment, 41, 8114-8127.

Du, S., 1997: Universality of the Lagrangian Velocity Structure Function Constant $\left(\mathrm{c}_{0}\right)$ Across Different Kinds of Turbulence. Boundary-Layer Meteorology, 83, 207-219.

Eichhorn, J.,1996: Validation of a microscale pollution dispersal model. In: Proceedings of the $21^{\text {st }}$ International Meeting on Air Modelling and its Application.

Fackrell, J.E. and A.G. Robins, 1982: Concentration fluctuations and fluxes in plumes from point sources in a turbulent boundary layer. Journal of Fluid Mechanics, 117, 1-26.

Li, G., S.-W. Wang and H. Rabitz, 2002a: Practical Approaches to Construct RS-HDMR Component Functions. Journal of Physical Chemistry A, 106, 8721-8733.

Li, G., S.-W. Wang, H. Rabitz, S. Wang, P. Jaffé, 2002b: Global uncertainty assessment by high dimensional model represenstations (HDMR). Chemical Engineering Science, 57, 4445-4460.

Lien, R.-C. and E.A. D’Asaro, 2002: The Kolmogorov constant for the Lagrangian velocity spectrum and structure function. Physics of Fluids, 14, 4456-4459.

Pavageau, M. and M. Schatzmann, 1999: Wind tunnel measurements of concentration fluctuations in an urban street canyon. Atmospheric Environment, 33, 3961-3971.

Rabitz, H., Ö.F. Ali , J. Shorter and K. Shim, 1999: Efficient input-output model representations. Computer Physics Communications, 117, 11-20.

Reynolds, A.M., (1998) Comments on the 'Universality of the Lagrangian velocity structure function constant $\left(\mathrm{C}_{0}\right)$ across different kinds of turbulence'. Boundary-Layer Meteorology. 89, 161-170.

Rizza, U., C. Mangia, J.C. Carvalho and D. Anfossi, 2006: Estimation of the Lagrangian Velocity Structure Function Constant $\mathrm{C}_{0}$ by Large-Eddy Simulation. Boundary-Layer Meteorology, 120, 25-37.

Shetter, R.E., A.H. McDaniel, C.A. Cantrell, S. Madronich and J.G. Calvert, 1992. Actinometer and Eppley Radiometer Measurement of $\mathrm{NO}_{2}$ Photolysis Rate Coefficient During the Mauna Loa Observatory Photochemistry Experiment. Journal of Geophysical Research, 97, 10349-10359.

Shetter, R.E., C.A. Cantrell, K.O. Lantz, S.J. Flocke, J.J. Orlando, G.S. Tyndall, T.M. Gilpin, C.A. Fischer, S. Madronich, J.G. Calvert and W. Junkermann, 1996: Actinometric and radiometric measurement and modelling of the photolysis rate coefficient of ozone to $\mathrm{O}\left({ }^{1} D\right)$ during Mauna Loa Observatory Photochemistry Experiment 2. Journal of Geophysical Research, 101, 14631-14641.

Thomson, D.J., 1987: Criteria for the selection of stochastic models of particle trajectories in turbulent flows. Journal of Fluid Mechanics, 180, 529-556.

Ziehn, T. and A.S. Tomlin, 2008a: Global sensitivity analysis of a 3D street canyon model - Part I: The development of high dimensional model representations. Atmospheric Environment, 42, 1857-1873.

Ziehn, T. and A.S. Tomlin, 2008b: A global sensitivity study of sulphur chemistry in a premixed methane flame model using HDMR. International Journal of Chemical Kinetics, In press.

Ziehn, T. and A.S. Tomlin, 2008c: GUI-HDMR - A Software Tool for Global Sensitivity Analysis of Complex Models. Environmental Modelling \& Software, Under review. 